\title{
Mixed duopolies with advance production
}

\author{
Tamás László Balogh \\ Department of Economic Analysis and Business Informatics, \\ University of Debrecen and \\ Attila Tasnádi \\ MTA-BCE "Lendület" Strategic Interactions Research Group, \\ Department of Mathematics, Corvinus University of Budapest
}

June 30, 2013

\begin{abstract}
Production to order and production in advance has been compared in many frameworks. In this paper we investigate a mixed production in advance version of the capacity-constrained Bertrand-Edgeworth duopoly game and determine the solution of the respective timing game. We show that a pure-strategy (subgame-perfect) Nashequilibrium point exists for all possible orderings of moves. It is pointed out that unlike the production-to-order case, the equilibrium of the timing game lies at simultaneous moves. An analysis of the public firm's impact on social welfare is also carried out. All the results are compared to those of the production-to order version of the respective game.
\end{abstract}

Keywords: Bertrand-Edgeworth, mixed duopoly, timing games.

JEL Classification Number: D43, L13.

\section{Introduction}

We can distinguish between production-in-advance (PIA) and production-to-order (PTO) concerning how the firms organize their production in order to satisfy the consumers' demand. ${ }^{1}$ In the former case production takes place before sales are realized, while in the latter one sales are determined before production takes place. Markets of perishable goods are usually mentioned as examples of advance production in a market. Phillips, Menkhaus, and Krogmeier (2001) emphasized that there are also goods which can be traded both in a PIA and in a PTO environment since PIA markets can be regarded as a kind of spot market whereas PTO markets as a kind of forward market. For example, coal and electricity are sold in both types of environments.

The comparison of the PIA and PTO environments have been carried out in experimental and theoretical frameworks for standard oligopolies. ${ }^{2}$ For instance, assuming strictly increasing marginal cost functions Mestelman, Welland, and Welland (1987) found that in an experimental posted offer market the firms' profits are lower in case of PIA. For more recent experimental analyses of the PIA environment we refer to Cracau and Franz (2012)

\footnotetext{
${ }^{1}$ The PIA game is also frequently called the price-quantity game or briefly PQ-game.

${ }^{2}$ We call an oligopoly standard if all firms are profitmaximizers, which basically means that they are privately owned.
} 
and Davis (2013). In a theoretical paper Shubik (1955) investigated the pure-strategy equilibrium of the PIA game and conjectured that the profits will be lower in case of PIA than in case of PTO. Levitan and Shubik (1978) and Gertner (1986) determined the mixed-strategy equilibrium for the constant unit cost case without capacity constraints. ${ }^{3}$ Assuming constant unit costs and identical capacity constraints, Tasnádi (2004) found that profits are identical in the two environments and that prices are higher under PIA than under PTO. In a recent paper Zhu, Wu, and Sun (2013) showed for the case of strictly convex cost functions that PIA equilibrium profits are higher than PTO equilibrium profits. In addition, considering different orders of moves and asymmetric cost functions Zhu, $\mathrm{Wu}$, and Sun (2013) demonstrated that the leader-follower PIA game leads to higher profit than the simultaneous-move PIA game. ${ }^{4}$

Concerning our theoretical setting, the closest paper is Tasnádi (2004) since we will investigate the constant unit case with capacity constraints. The main difference is that we will replace one profit-maximizing firm with a social welfare maximizing firm, that is we will consider a so-called mixed duopoly. We have already considered the PTO mixed duopoly in Balogh and Tasnádi (2012) for which we found (i) the payoff equivalence of the games with exogenously given order of moves, (ii) an increase in social welfare compared with the standard version of the game, and (iii) that an equilibrium in pure strategies always exists in contrast to the standard version of the game. In this paper we demonstrate for the PIA mixed duopoly the existence of an equilibrium in pure strategies, lower social welfare than in case of the PTO mixed duopoly and the emergence of simultaneous moves in the timing game.

It is also worthwhile to relate our paper briefly to the literature on mixed oligopolies. In a seminal paper Pal (1998) investigates for mixed oligopolies the endogenous emergence of certain orders of moves. Assuming linear demand and constant marginal costs, he shows for a quantity-setting oligopoly with one public firm that, in contrast to our result, the simultaneous-move case does not emerge. Matsumura (2003) relaxes the assumptions of linear demand and identical marginal costs employed by Pal (1998). The case of increasing marginal costs in Pal's (1998) framework has recently been investigated by Tomaru and Kiyono (2010). In line with our result on the timing of moves Bárcena-Ruiz (2007) obtained the endogenous emergence of simultaneous moves for a heterogeneous goods price-setting mixed duopoly timing game.

The remainder of the paper is organized as follows. In Section 2 we present our framework, Section 3 contains the analysis of the three games with exogenously given order of moves, Section 4 solves the timing game, and we conclude in Section 5.

\section{The framework}

The demand is given by function $D$ on which we impose the following restrictions:

Assumption 1. The demand function $D$ intersects the horizontal axis at quantity $a$ and the vertical axis at price $b . D$ is strictly decreasing, concave and twice continuously differentiable on $(0, a)$; moreover, $D$ is right-continuous at 0 , left-continuous at $b$ and $D(p)=0$ for all $p \geq b$.

\footnotetext{
${ }^{3}$ Gertner (1986) also derived some important properties of the mixed-strategy equilibrium of the PIA game for strictly convex cost functions. For more on the PIA case see also van den Berg and Bos (2011).

${ }^{4}$ From the mentioned papers only $\mathrm{Zhu}, \mathrm{Wu}$, and Sun (2013) considered sequential orders of moves. For more on leader-follower games we refer to Boyer and Moreaux (1987), Deneckere and Kovenock (1992) and Tasnádi (2003) in the Bertrand-Edgeworth framework.
} 
Clearly, any price-setting firm will not set its price above $b$. Let us denote by $P$ the inverse demand function. Thus, $P(q)=D^{-1}(q)$ for $0<q \leq a, P(0)=b$, and $P(q)=0$ for $q>a$.

On the producers side we have a public firm and a private firm, that is, we consider a so-called mixed duopoly. We label the public firm with 1 and the private firm with 2 . Henceforth, we will also label the two firms by $i$ and $j$, where $i, j \in\{1,2\}$ and $i \neq j$. Our assumptions imposed on the firms' cost functions are as follows:

Assumption 2. The two firms have positive identical $c$ unit costs up to the positive capacity constraints $k_{1}, k_{2}$ respectively.

We shall denote by $p^{c}$ the market clearing price and by $p^{M}$ the price set by a monopolist without capacity constraints, i.e. $p^{c}=P\left(k_{1}+k_{2}\right)$ and $p^{M}=\arg \max _{p \in[0, b]}(p-c) D(p)$. In what follows $p_{1}, p_{2} \in[0, b]$ and $q_{1}, q_{2} \in[0, a]$ stand for the prices and quantities set by the firms.

For any firm $i$ and for any quantity $q_{j}$ set by its opponent $j$ we shall denote by $p_{i}^{m}\left(q_{j}\right)$ the unique profit maximizing price on the firms' residual demand curves $D_{i}^{r}\left(p, q_{j}\right)=\left(D(p)-q_{j}\right)^{+}$, i.e. $\bar{p}_{i}\left(q_{j}\right)=\arg \max _{p \in[0, b]}(p-c) D_{i}^{r}\left(p, q_{j}\right)$, where in the definition of $\bar{p}_{i}\left(q_{j}\right)$ we do not include the capacity constraint of firm $i$. For notational convenience we also introduce $p_{i}^{m}\left(q_{j}\right)$ as the price maximizing profits with respect to the residual demand curve subject to the capacity constraint of firm $i$. Clearly, $p^{c}, \bar{p}_{i}$ and $p_{i}^{m}$ are well defined whenever $c<P\left(q_{j}\right)$ and Assumptions 1-2 are satisfied. In addition, let $\bar{p}_{i}\left(q_{j}\right)=p_{i}^{m}\left(q_{j}\right)=c$ if $c \geq P\left(q_{j}\right)$. For a given quantity $q_{j}$ we shall denote the inverse residual demand curve of firm $i$ by $R_{i}\left(\cdot, q_{j}\right)$. It can be checked that $R_{i}\left(q_{i}, q_{j}\right)=P\left(q_{i}+q_{j}\right)$ and $p_{i}^{m}\left(q_{j}\right)=\max \left\{\bar{p}_{i}\left(q_{j}\right), R_{i}\left(k_{i}, q_{j}\right)\right\}$. Let $\bar{q}_{i}\left(q_{j}\right)=\arg \max _{q_{i} \in[0, a]}\left(R_{i}\left(q_{i}, q_{j}\right)-c\right) q_{i}$ and $q_{i}^{m}\left(q_{j}\right)=\min \left\{\bar{q}_{i}\left(q_{j}\right), k_{i}\right\}$. Clearly, $\bar{q}_{i}\left(q_{j}\right)=D_{i}^{r}\left(\bar{p}_{i}\left(q_{j}\right), q_{j}\right)$ and $q_{i}^{m}\left(q_{j}\right)=D_{i}^{r}\left(p_{i}^{m}\left(q_{j}\right), q_{j}\right)$.

Let us denote by $p_{i}^{d}\left(q_{j}\right)$ the smallest price for which

$$
\left(p_{i}^{d}\left(q_{j}\right)-c\right) \min \left\{k_{i}, D\left(p_{i}^{d}\left(q_{j}\right)\right)\right\}=\left(p_{i}^{m}\left(q_{j}\right)-c\right) q_{i}^{m}\left(q_{j}\right)
$$

whenever this equation has a solution. ${ }^{5}$ Provided that the private firm has 'sufficient' capacity, that is $\max \left\{p^{c}, c\right\}<p_{2}^{m}\left(k_{1}\right)$, then if it is a profitmaximizer, it is indifferent to whether serving residual demand at price level $p_{2}^{m}\left(q_{1}\right)$ or selling $\min \left\{k_{2}, D\left(p_{2}^{d}\left(q_{1}\right)\right)\right\}$ at the lower price level $p_{2}^{d}\left(q_{1}\right)$. Observe that if $R_{i}\left(k_{i}, q_{j}\right) \geq \bar{p}_{i}\left(q_{j}\right)$, then $p_{i}^{d}\left(q_{j}\right)=p_{i}^{m}\left(q_{j}\right) .{ }^{6}$ We shall denote by $\tilde{q}_{j}$ the quantity for which $\bar{q}_{i}\left(\tilde{q}_{j}\right)=k_{i}$ in case of $p^{M}<P\left(k_{i}\right)$ and $\bar{q}_{i}\left(k_{j}\right) \leq k_{i}{ }^{7}$ In addition, let $\tilde{q}_{j}=0$ if $p^{M} \geq P\left(k_{i}\right)$ and $\tilde{q}_{j}=k_{j}$ if $\bar{q}_{i}\left(k_{j}\right)>k_{i}$. From Deneckere and Kovenock (1992, Lemma 1$)$ it follows that $p_{i}^{d}(\cdot)$ is strictly decreasing and it can be also verified that $\bar{p}_{i}(\cdot), \bar{q}_{i}(\cdot)$, and $p_{i}^{m}(\cdot)$ are also strictly decreasing. Moreover, $q_{i}^{m}(\cdot)$ is strictly decreasing on $\left[\tilde{q}_{j}, k_{j}\right]$ and constant on $\left[0, \tilde{q}_{j}\right]$.

We assume efficient rationing on the market, and thus, the firms' demands equal

$$
\Delta_{i}\left(D, p_{1}, q_{1}, p_{2}, q_{2}\right)= \begin{cases}D\left(p_{i}\right) & \text { if } p_{i}<p_{j} \\ \frac{q_{i}}{q_{1}+q_{2}} D(p) & \text { if } p=p_{i}=p_{j} \\ \left(D\left(p_{i}\right)-q_{j}\right)^{+} & \text {if } p_{i}>p_{j}\end{cases}
$$

\footnotetext{
${ }^{5}$ The equation defining $p_{i}^{d}\left(q_{j}\right)$ has a solution for any $q_{j} \in\left[0, k_{j}\right]$ if, for instance, $\bar{p}_{i}\left(k_{j}\right) \geq \max \left\{p^{c}, c\right\}$, which will be the case in our analysis when we will refer to $p_{i}^{d}\left(q_{j}\right)$.

${ }^{6}$ This can be the case if $p^{M}<P\left(k_{i}\right)$.

${ }^{7}$ The second case does not occur if $\bar{p}_{i}\left(k_{j}\right)>\max \left\{p^{c}, c\right\}$.
} 
where if the firms set identical prices, we assume that the demand is allocated in proportion of the firms' production.

Now we specify the firms objective functions. The public firm aims at maximizing total surplus, that is,

$$
\pi_{1}\left(p_{1}, q_{1}, p_{2}, q_{2}\right)=\int_{0}^{\min \left\{\left(D\left(p_{j}\right)-q_{i}\right)^{+}, q_{j}\right\}} R_{j}\left(q, q_{i}\right) d q+\int_{0}^{\min \left\{a, q_{i}\right\}} P(q) d q-c\left(q_{1}+q_{2}\right),
$$

where $0 \leq p_{i} \leq p_{j} \leq b$. The private firm is a profitmaximizer, and therefore,

$$
\pi_{2}\left(p_{1}, q_{1}, p_{2}, q_{2}\right)=p_{2} \min \left\{k_{2}, \Delta_{2}\left(D, p_{1}, q_{1}, p_{2}, q_{2}\right)\right\}-c q_{2} .
$$

In the present paper we investigate the most interesting and difficult case identified by our results on the PTO game (see Balogh and Tasnádi, 2012). In particular, we assume that the private firm's capacity is large enough to have strategic influence on the outcome.

Assumption 3. Let $\bar{p}_{2}\left(k_{1}\right)>\max \left\{p^{c}, c\right\}$.

\section{Equilibrium analysis}

We now determine all the equilibrium strategies of both firms for the three possible orderings of moves. We begin with the simultaneous-move case, thereafter we focus on the public-firm-moves-first case, finally we analyze the private-firm-moves-first case.

The following two inequalities remain true for all three cases, therefore we do not discuss them separately in each subsection.

Lemma 1. Under Assumptions 1-3 we must have

$$
p_{2}^{*} \geq p_{2}^{d}\left(q_{1}^{*}\right)
$$

in any equilibrium $\left(p_{1}^{*}, q_{1}^{*}, p_{2}^{*}, q_{2}^{*}\right)$.

Proof. We obtain the result directly from the definition of $p_{2}^{d}\left(q_{1}\right)$. For any $q_{1} \in\left[0, k_{1}\right]$, the private firm is better off by setting $p_{2}=p_{2}^{m}\left(q_{1}\right)$ and $q_{2}=q_{2}^{m}\left(q_{1}\right)$, than by setting any price $p_{2}<p_{2}^{d}\left(q_{1}\right)$ and any quantity $q_{2} \in\left[0, k_{2}\right]$.

Lemma 2. Under Assumptions 1-3 we have

$$
p_{2}^{*} \leq \max \left\{P\left(k_{2}\right), p^{M}\right\}
$$

in any equilibrium $\left(p_{1}^{*}, q_{1}^{*}, p_{2}^{*}, q_{2}^{*}\right)$.

Proof. If the public firm is not present on the market (i.e. $\left.q_{1}^{*}=0\right)$, then the private firm's best reply is $\left(p_{2}^{*}, q_{2}^{*}\right)=\left(\max \left\{P\left(k_{2}\right), p^{M}\right\}, D\left(\max \left\{P\left(k_{2}\right), p^{M}\right\}\right)\right)$.

Assume that the public firm is present on the market (i.e. $q_{1}^{*}>0$ ). We prove (4) by contradiction. Suppose that $p_{2}^{*}>\max \left\{P\left(k_{2}\right), p^{M}\right\}$. If $p_{2}^{*}<p_{1}^{*}$, then we must have $q_{2}^{*}=D\left(p_{2}^{*}\right)$ and the superfluous production by the public firm is reducing social welfare. If $p_{2}^{*}=p_{1}^{*}$, then the private firm could gain by undercutting the public firm's price and satisfying the entire demand. Finally, if $p_{2}^{*}>p_{1}^{*}$, then the private firm serves residual demand, and therefore switching to either action $\left(\bar{p}_{2}\left(q_{1}^{*}\right), \bar{q}_{2}\left(q_{1}^{*}\right)\right)$ or action $\left(R_{2}\left(k_{2}, q_{1}^{*}\right), k_{2}\right)$ will be beneficial for the private firm, implying a price reduction since by definition $\bar{p}_{2}\left(q_{1}^{*}\right)<$ $p^{M}$ and $R_{2}\left(k_{2}, q_{1}^{*}\right)<P\left(k_{2}\right) .{ }^{8}$

\footnotetext{
${ }^{8}$ The former case determines the reduced price if $\bar{q}_{2}\left(q_{1}^{*}\right) \leq k_{2}$, while the latter one if $\bar{q}_{2}\left(q_{1}^{*}\right)>k_{2}$.
} 


\subsection{Simultaneous moves}

Proposition 1 (Simultaneous moves). Let Assumptions 1-3 be satisfied. A strategy profile

$$
\left(p_{1}^{*}, q_{1}^{*}, p_{2}^{*}, q_{2}^{*}\right)=\left(p_{1}^{*}, q_{1}^{*}, p_{2}^{m}\left(q_{1}^{*}\right), q_{2}^{m}\left(q_{1}^{*}\right)\right)
$$

is for a quantity $q_{1}^{*} \in\left[0, k_{1}\right]$ and for any price $p_{1}^{*} \in\left[0, p_{2}^{d}\left(q_{1}^{*}\right)\right]$ a Nash-equilibrium in pure strategies if and only if

$$
\pi_{1}\left(p_{2}^{d}\left(q_{1}^{*}\right), q_{1}^{*}, p_{2}^{m}\left(q_{1}^{*}\right), q_{2}^{m}\left(q_{1}^{*}\right)\right) \geq \pi_{1}\left(P\left(k_{1}\right), k_{1}, p_{2}^{m}\left(q_{1}^{*}\right), q_{2}^{m}\left(q_{1}^{*}\right)\right),
$$

where there exists a nonempty closed subset $H$ of $\left[0, k_{1}\right]$ satisfying condition (6). ${ }^{9}$ Moreover, if $\pi_{1}\left(p_{2}^{\prime}, 0, p_{2}^{\prime}, q_{2}^{\prime}\right) \geq \pi_{1}\left(P\left(k_{1}\right), k_{1}, p_{2}^{\prime}, q_{2}^{\prime}\right)$, where $p_{2}^{\prime}=\max \left\{P\left(k_{2}\right), p^{M}\right\}$ and $q_{2}^{\prime}=$ $D\left(\max \left\{P\left(k_{2}\right), p^{M}\right\}\right)$, then for all $p_{1} \in[0, b]$

$$
\left(p_{1}^{*}, q_{1}^{*}, p_{2}^{*}, q_{2}^{*}\right)=\left(p_{1}, 0, p_{2}^{\prime}, q_{2}^{\prime}\right)
$$

are also equilibrium profiles. ${ }^{10}$ Finally, no other equilibrium in pure strategies exists.

Proof. Assume that $\left(p_{1}^{*}, q_{1}^{*}, p_{2}^{*}, q_{2}^{*}\right)$ is an arbitrary equilibrium profile. We divide our analysis into three subcases. In the first case (Case A) we have $p_{1}^{*}=p_{2}^{*}$, in the second one (Case B) $p_{1}^{*}>p_{2}^{*}$ holds true, while in the remaining case we have $p_{1}^{*}<p_{2}^{*}$ (Case C).

Case A: We claim that $p_{1}^{*}=p_{2}^{*}$ implies $q_{1}^{*}+q_{2}^{*}=D\left(p_{2}^{*}\right)$. Suppose that $q_{1}^{*}+q_{2}^{*}<D\left(p_{2}^{*}\right)$. Then because of $p_{2}^{*}>\max \left\{p^{c}, c\right\}$ by a unilateral increase in output the public firm could increase social welfare or the private firm could increase its profit; a contradiction. Suppose that $q_{1}^{*}+q_{2}^{*}>D\left(p_{2}^{*}\right)$. Then the public firm could increase social welfare by decreasing its output or if $q_{1}^{*}=0$, the private firm could increase its profit by producing $D\left(p_{2}^{*}\right)$; a contradiction.

We know that we must have $p_{1}^{*}=p_{2}^{*} \geq p_{2}^{d}\left(q_{1}^{*}\right)$ by Lemma 1 . Then we must have $q_{2}^{*}=\min \left\{k_{2}, D\left(p_{2}^{*}\right)\right\}$, since otherwise the private firm could benefit from reducing its price slightly and increasing its output sufficiently (in particular, by setting $p_{2}=p_{2}^{*}-\varepsilon$ and $\left.q_{2}^{*}=\min \left\{k_{2}, D\left(p_{2}\right)\right\}\right)$. Assume that $q_{1}^{*}>0$. Observe that $p_{2}^{m}(0)=p_{2}^{d}(0)=p_{2}^{\prime}$, $p_{2}^{m}\left(q_{1}\right)=p_{2}^{d}\left(q_{1}\right)$ for all $q_{1} \in\left[0, \tilde{q}_{1}\right]$ and $p_{2}^{m}\left(q_{1}\right)>p_{2}^{d}\left(q_{1}\right)$ for all $q_{1} \in\left(\tilde{q}_{1}, k_{1}\right]$. Moreover, it can be verified by the definitions of $p_{2}^{m}\left(q_{1}^{*}\right)$ and $p_{2}^{d}\left(q_{1}^{*}\right)$ that $q_{1}^{*}+k_{2} \geq D\left(p_{2}^{d}\left(q_{1}^{*}\right)\right) \geq D\left(p_{2}^{*}\right)$, where the first inequality is strict if $q_{1}^{*}>\tilde{q}_{1}$. Thus, $q_{1}^{*}>\tilde{q}_{1}$ is in contradiction with $q_{2}^{*}=\min \left\{k_{2}, D\left(p_{2}^{*}\right)\right\}$ since we already know that $q_{1}^{*}+q_{2}^{*}=D\left(p_{2}^{*}\right)$ in Case A. Hence, an equilibrium in which both firms set the same price and the public firm's output is positive exists if and only if $p_{2}^{m}\left(q_{1}^{*}\right)=p_{2}^{d}\left(q_{1}^{*}\right)$ (i.e., $\left.q_{1}^{*} \in\left(0, \tilde{q}_{1}\right)\right)$ and $(6)$ is satisfied. This type of equilibria appear in (5).

Moreover, it can be verified that $\left(p_{1}^{*}, q_{1}^{*}, p_{2}^{*}, q_{2}^{*}\right)=\left(p_{2}^{\prime}, 0, p_{2}^{\prime}, q_{2}^{\prime}\right)$ is an equilibrium profile in pure strategies if and only if

$$
\pi_{1}\left(p_{2}^{\prime}, 0, p_{2}^{\prime}, q_{2}^{\prime}\right) \geq \pi_{1}\left(P\left(k_{1}\right), k_{1}, p_{2}^{\prime}, q_{2}^{\prime}\right),
$$

where $p_{2}^{\prime}=\max \left\{P\left(k_{2}\right), p^{M}\right\}$ and $q_{2}^{\prime}=D\left(\max \left\{P\left(k_{2}\right), p^{M}\right\}\right)$.

Case B: Suppose that $p_{1}^{*}>p_{2}^{*} \geq p_{2}^{d}\left(q_{1}^{*}\right)$ and $D\left(p_{2}^{*}\right)>q_{2}^{*}$. Then the public firm could increase social welfare by setting price $p_{1}=p_{2}^{*}$ and $q_{1}=D\left(p_{2}^{*}\right)-q_{2}^{*}$; a contradiction.

\footnotetext{
${ }^{9}$ In particular, there exists a subset $\left[\bar{q}, k_{1}\right]$ of $H$.

${ }^{10}$ We remark that the cases with $p_{1} \leq p_{2}^{\prime}$ are also included in (5).
} 
Assume that $p_{1}^{*}>p_{2}^{*} \geq p_{2}^{d}\left(q_{1}^{*}\right)$ and $D\left(p_{2}^{*}\right)=q_{2}^{*}$. Then in an equilibrium we must have $q_{1}^{*}=0, p_{2}^{*}=p_{2}^{\prime}$ and $q_{2}^{*}=q_{2}^{\prime}$. Furthermore, it can be checked that these profiles specify equilibrium profiles if and only if equation (8) is satisfied.

Clearly, $p_{1}^{*}>p_{2}^{*} \geq p_{2}^{d}\left(q_{1}^{*}\right)$ and $D\left(p_{2}^{*}\right)<q_{2}^{*}$ cannot be the case in an equilibrium since the private firm could increase its profit by producing $q_{2}=D\left(p_{2}^{*}\right)$ at price $p_{2}^{*}$.

Case C: In this case $p_{2}^{*}=p_{2}^{m}\left(q_{1}^{*}\right)$ and $q_{2}^{*}=q_{2}^{m}\left(q_{1}^{*}\right)$ must hold, since otherwise the private firm's payoff would be strictly lower. In particular, if the private firm sets a price not greater than $p_{1}^{*}$, we are not anymore in Case C. Furthermore, if $q_{2}^{*}>D_{2}^{r}\left(p_{2}^{*}, q_{1}^{*}\right)$, then the private firm produces a superfluous amount; if $q_{2}^{*}<\min \left\{D_{2}^{r}\left(p_{2}^{*}, q_{1}^{*}\right), k_{2}\right\}$, then the private firm could still sell more than $q_{2}^{*}$; and if $q_{2}^{*}=\min \left\{D_{2}^{r}\left(p_{2}^{*}, q_{1}^{*}\right), k_{2}\right\}$, then the private firm will choose a price-quantity pair maximizing profits with respect to its residual demand curve $D_{2}^{r}\left(\cdot, q_{1}^{*}\right)$ subject to its capacity constraint. In addition, in order to prevent the private firm from undercutting the public firm's price we must have $p_{1}^{*} \leq p_{2}^{d}\left(q_{1}^{*}\right)$.

Clearly, for the given values $p_{1}^{*}, p_{2}^{*}$ and $q_{2}^{*}$ from our equilibrium profile the public firm has to choose a quantity $q_{1}^{\prime} \in\left[0, k_{1}\right]$, which maximizes function $f\left(q_{1}\right)=\pi_{1}\left(p_{1}^{*}, q_{1}, p_{2}^{*}, q_{2}^{*}\right)$ on $\left[0, k_{1}\right]$. We show that $q_{1}^{\prime}=q_{1}^{*}$ must be the case. Obviously, it does not make sense for the public firm to produce less than $q_{1}^{*}$ since this would result in unsatisfied consumers. Observe that for all $q_{1} \in\left[q_{1}^{*}, \min \left\{D\left(p_{2}^{*}\right), k_{1}\right\}\right]$

$$
\begin{aligned}
f\left(q_{1}\right) & =\int_{0}^{D\left(p_{2}^{*}\right)-q_{1}}\left(R_{2}\left(q, q_{1}\right)-c\right) d q+\int_{0}^{q_{1}}(P(q)-c) d q-c\left(q_{1}-q_{1}^{*}\right)= \\
& =\int_{0}^{D\left(p_{2}^{*}\right)} P(q) d q-D\left(p_{2}^{*}\right) c-c\left(q_{1}-q_{1}^{*}\right) .
\end{aligned}
$$

Since only $-c\left(q_{1}-q_{1}^{*}\right)$ is a function of $q_{1}$ we see that $f$ is strictly decreasing on $\left[q_{1}^{*}, \min \left\{D\left(p_{2}^{*}\right), k_{1}\right\}\right]$.

Subase (i): In case of $k_{1} \leq D\left(p_{2}^{*}\right)$ we have already established that $q_{1}^{*}$ maximizes $f$ on $\left[0, k_{1}\right]$. Moreover, $\left(p_{1}^{*}, q_{1}^{*}\right)$ maximizes $\pi_{1}\left(p_{1}, q_{1}, p_{2}^{*}, q_{2}^{*}\right)$ on $\left[0, p_{2}^{*}\right) \times\left[0, k_{1}\right]$ since equation (9) is not a function of $p_{1}^{*}$. Hence, for any $p_{1}<p_{2}^{*}$ and $p_{1} \leq p_{2}^{d}\left(q_{1}^{*}\right)$ we have that $\left(p_{1}, q_{1}^{*}, p_{2}^{m}\left(q_{1}^{*}\right), q_{2}^{m}\left(q_{1}^{*}\right)\right)$ specifies a Nash equilibrium for any $q_{1} \in\left(0, k_{1}\right]$ satisfying $k_{1} \leq D\left(p_{2}^{m}\left(q_{1}^{*}\right)\right)$. However, note that in case of $q_{1}^{*} \in\left[0, \tilde{q}_{1}\right]$ and $p_{1}=p_{2}^{d}\left(q_{1}^{*}\right)$ we are leaving Case $\mathrm{C}$ and obtain a Case A Nash equilibrium.

Observe that $p_{2}^{m}\left(k_{1}\right)>\max \left\{p^{c}, c\right\}$ implies that $k_{1}<D\left(p_{2}^{m}\left(k_{1}^{*}\right)\right)$, and therefore we always have Subcase (i) equilibrium profiles. If $k_{1}=D\left(p_{2}^{m}\left(q_{1}\right)\right)$ has a solution for $q_{1} \in$ $\left[0, k_{1}\right)$, then we shall denote its solution by $\widetilde{q}$, and otherwise let $\widetilde{q}=0$. Since $D\left(p_{2}^{m}(\cdot)\right)$ is a continuous and strictly increasing function, interval $\left[\widetilde{q}, k_{1}\right] \cap\left(0, k_{1}\right]$ determines the set of quantities yielding an equilibrium for Subcase (i).

Subase (ii): Turning to the more complicated case of $k_{1}>D\left(p_{2}^{*}\right)$, we also have to investigate function $f$ above the interval $\left[D\left(p_{2}^{*}\right), k_{1}\right]$ in which region the private firm does not sell anything at all at price $p_{2}^{*}$ and

$$
f\left(q_{1}\right)=\int_{0}^{\min \left\{q_{1}, D\left(p_{1}^{*}\right)\right\}}(P(q)-c) d q-c q_{2}^{*}-c\left(q_{1}-D\left(p_{1}^{*}\right)\right)^{+} .
$$

Observe that we must have $P\left(k_{1}\right)<p_{2}^{*}$. If the public firm is already producing quantity $q_{1}=D\left(p_{2}^{*}\right)$, the private firm does not sell anything at all and contributes to a social loss of $c q_{2}^{*}$. Therefore, $f(q)$ is increasing on $\left[D\left(p_{2}^{*}\right), \min \left\{D\left(p_{1}^{*}\right), k_{1}\right\}\right]$. 
Assume that $k_{1} \leq D\left(p_{1}^{*}\right)$. Then for any $p_{1} \leq p_{2}^{d}\left(q_{1}^{*}\right)$ we get that $\left(p_{1}, q_{1}^{*}, p_{2}^{m}\left(q_{1}^{*}\right), q_{2}^{m}\left(q_{1}^{*}\right)\right)$ is a Nash equilibrium if and only if

$$
\begin{aligned}
\pi_{1}\left(p_{2}^{d}\left(q_{1}^{*}\right), q_{1}^{*}, p_{2}^{m}\left(q_{1}^{*}\right), q_{2}^{m}\left(q_{1}^{*}\right)\right) & \geq \pi_{1}\left(p_{2}^{d}\left(q_{1}^{*}\right), k_{1}, p_{2}^{m}\left(q_{1}^{*}\right), q_{2}^{m}\left(q_{1}^{*}\right)\right)= \\
& =\pi_{1}\left(P\left(k_{1}\right), k_{1}, p_{2}^{m}\left(q_{1}^{*}\right), q_{2}^{m}\left(q_{1}^{*}\right)\right),
\end{aligned}
$$

where the last equality follows from the fact that social welfare is maximized in function of $\left(p_{1}, q_{1}\right)$ subject to the constraint that the private firm does not sell anything at all if the public firm sets an arbitrary price not greater than $P\left(k_{1}\right)$ and produces $k_{1}$.

Assume that $k_{1}>D\left(p_{1}^{*}\right)$. Therefore, $f(q)$ would be decreasing on $\left[D\left(p_{1}^{*}\right), k_{1}\right]$. However, it can be checked that the public firm could increase social welfare by switching to strategy $\left(P\left(k_{1}\right), k_{1}\right)$ from strategy $\left(p_{1}^{*}, D\left(p_{1}^{*}\right)\right)$. In addition, any strategy $\left(p_{1}, k_{1}\right)$ with $p_{1} \leq P\left(k_{1}\right)$ maximizes social welfare subject to the constraint that the private firm does not sell anything at all. Therefore, $\left(p_{2}^{d}\left(q_{1}^{*}\right), q_{1}^{*}, p_{2}^{m}\left(q_{1}^{*}\right), q_{2}^{m}\left(q_{1}^{*}\right)\right)$ is a Nash equilibrium if and only if condition (6) is satisfied. Comparing equation (11) with equation (6), we can observe that we have derived the same necessary and sufficient condition for a strategy profile being a Nash equilibrium, which is valid for Subcase (ii).

So far we have established that there exists a function $g$, which uniquely determines the highest equilibrium price as a function of quantity $q$ produced by the public firm. Clearly, $g(q)=p_{2}^{d}(q)$, where the domain of $g$ is not entirely specified. At least we know from Subcase (i) that the domain of $g$ contains $\left[\widetilde{q}, k_{1}\right]$. Observe also that the equilibrium profiles of Subcase (i) satisfy condition (6). Let $u\left(q_{1}\right)=\pi_{1}\left(p_{2}^{d}\left(q_{1}\right), q_{1}, p_{2}^{m}\left(q_{1}\right), q_{2}^{m}\left(q_{1}\right)\right)$ and $v\left(q_{1}\right)=\pi_{1}\left(P\left(k_{1}\right), k_{1}, p_{2}^{m}\left(q_{1}\right), q_{2}^{m}\left(q_{1}\right)\right)$. Hence, $q_{1}$ determines a Nash equilibrium profile if and only if $u\left(q_{1}\right) \geq v\left(q_{1}\right)$. It can be verified that $u$ and $v$ are continuous, and therefore, set $H=\left\{q \in\left[0, k_{1}\right] \mid u(q) \geq v(q)\right\}$ is a closed set containing $\left[\widetilde{q}, k_{1}\right]$.

\subsection{Public firm moves first}

We continue with the case of public leadership.

Proposition 2 (Public firm moves first). Let Assumptions 1-3 be satisfied. Then the set of SPNE prices and quantities are given by

$$
\left(p_{1}^{*}, q_{1}^{*}, p_{2}^{*}, q_{2}^{*}\right)=\left(p_{1}, k_{1}, p_{2}^{m}\left(k_{1}\right), q_{2}^{m}\left(k_{1}\right)\right)
$$

for any $p_{1} \leq p_{2}^{d}\left(k_{1}\right)$.

Proof. First, we determine the best reply (or more precisely, the almost best reply) $B R_{2}=\left(p_{2}^{*}(\cdot, \cdot), q_{2}^{*}(\cdot, \cdot)\right)$ of the private firm. Observe that the private firm's best response correspondence can be obtained from the proof of Proposition 1. Assuming that $q_{1}>0,{ }^{11}$ $B R_{2}\left(p_{1}, q_{1}\right)=$

$$
\begin{cases}\left(p_{2}^{m}\left(q_{1}\right), q_{2}^{m}\left(q_{1}\right)\right) & \text { if } p_{1} \leq p_{2}^{d}\left(q_{1}\right) \\ \left(p_{1}, \min \left\{k_{2}, D\left(p_{2}\right)\right\}\right)-\varepsilon & \text { if } p_{2}^{d}\left(q_{1}\right)<p_{1} \leq \max \left\{P\left(k_{2}\right), p^{M}\right\} \\ \left(\max \left\{P\left(k_{2}\right), p^{M}\right\}, D\left(\max \left\{P\left(k_{2}\right), p^{M}\right\}\right)\right) & \text { if } \max \left\{P\left(k_{2}\right), p^{M}\right\}<p_{1} .\end{cases}
$$

for an arbitrarily small positive value $\varepsilon$. In fact the best reply does not exist if $p_{2}^{d}\left(q_{1}\right)<$ $p_{1} \leq \max \left\{P\left(k_{2}\right), p^{M}\right\}$ since the private firm will undercut the public firm's price. However, this does not pose a problem since the public firm chooses a first stage action such that $p_{1} \leq p_{2}^{d}\left(q_{1}\right)$. In particular, the public firm maximizes social welfare in the first period by choosing price $p_{1}^{*}=p_{2}^{d}\left(k_{1}\right)$ and quantity $k_{1}$.

\footnotetext{
${ }^{11}$ It is easy to see that if $q_{1}=0$, then $B R_{2}\left(p_{1}, 0\right)=\left(\max \left\{P\left(k_{2}\right), p^{M}\right\}, D\left(\max \left\{P\left(k_{2}\right), p^{M}\right\}\right)\right)$.
} 


\subsection{Private firm moves first}

Now we consider the case of private leadership.

Proposition 3 (Private firm moves first). Let Assumptions 1-3 be satisfied. If $\pi_{1}\left(p_{2}^{\prime}, 0, p_{2}^{\prime}, q_{2}^{\prime}\right)>\pi_{1}\left(P\left(k_{1}\right), k_{1}, p_{2}^{\prime}, q_{2}^{\prime}\right)$, where $p_{2}^{\prime}=\max \left\{P\left(k_{2}\right), p^{M}\right\}$ and $q_{2}^{\prime}=$ $D\left(\max \left\{P\left(k_{2}\right), p^{M}\right\}\right)$, then the equilibrium actions of the firms associated with an SPNE are the following ones

$$
\left(p_{1}^{*}, q_{1}^{*}, p_{2}^{*}, q_{2}^{*}\right)=\left(p_{1}, 0, p_{2}^{\prime}, q_{2}^{\prime}\right)
$$

where $p_{1} \in[0, b]$ can be an arbitrary price. If $\pi_{1}\left(p_{2}^{\prime}, 0, p_{2}^{\prime}, q_{2}^{\prime}\right)<\pi_{1}\left(P\left(k_{1}\right), k_{1}, p_{2}^{\prime}, q_{2}^{\prime}\right)$, then the equilibrium actions of the firms associated with an SPNE are the following ones:

$$
\left(p_{1}^{*}, q_{1}^{*}, p_{2}^{*}, q_{2}^{*}\right)=\left(p_{1}, D_{1}^{r}\left(\tilde{p}_{2}, k_{2}\right), \tilde{p}_{2}, \min \left\{D\left(\tilde{p}_{2}\right), k_{2}\right\}\right)
$$

where $p_{1} \in\left[0, \tilde{p_{2}}\right]$ and

$$
\tilde{p_{2}}=\sup \left\{p_{2} \mid \pi_{1}\left(p_{1}, D_{1}^{r}\left(p_{2}, k_{2}\right), p_{2}, \min \left\{D\left(p_{2}\right), k_{2}\right) \geq \pi_{1}\left(P\left(k_{1}\right), k_{1}, p_{2}^{\prime}, q_{2}^{\prime}\right)\right\} .\right.
$$

In addition, if $\pi_{1}\left(p_{2}^{\prime}, 0, p_{2}^{\prime}, q_{2}^{\prime}\right)=\pi_{1}\left(P\left(k_{1}\right), k_{1}, p_{2}^{\prime}, q_{2}^{\prime}\right)$, then both (13) and (14) are SPNE.

Proof. If $\pi_{1}\left(p_{2}^{\prime}, 0, p_{2}^{\prime}, q_{2}^{\prime}\right)>\pi_{1}\left(P\left(k_{1}\right), k_{1}, p_{2}^{\prime}, q_{2}^{\prime}\right)$, then the private firm becomes a monopolist on the market or sells its entire capacity since this is the best outcome for the private firm which it can also enforce. Considering the other case $\pi_{1}\left(p_{2}^{\prime}, 0, p_{2}^{\prime}, q_{2}^{\prime}\right)<$ $\pi_{1}\left(P\left(k_{1}\right), k_{1}, p_{2}^{\prime}, q_{2}^{\prime}\right)$, just like in the previous sequential case, we determine the reaction function of the second mover, that is the best reply function $B R_{1}=\left(p_{1}^{*}(\cdot, \cdot), q_{1}^{*}(\cdot, \cdot)\right)$ of the public firm. $B R_{1}\left(p_{2}, q_{2}\right)=$

$$
\begin{cases}\left\{\left(p_{1}, D_{1}^{r}\left(p_{2}, q_{2}\right) \mid p_{1} \leq p_{2}\right)\right\} & \text { if } \pi_{1}\left(p_{1}, D_{1}^{r}\left(p_{2}, q_{2}\right), p_{2}, q_{2}\right)<\pi_{1}\left(P\left(k_{1}\right), k_{1}, p_{2}, q_{2}\right) \\ \left\{\left(p_{1}, k_{1}\right) \mid p_{1} \leq P\left(k_{1}\right)\right\} & \text { if } \pi_{1}\left(p_{1}, D_{1}^{r}\left(p_{2}, q_{2}\right), p_{2}, q_{2}\right)>\pi_{1}\left(P\left(k_{1}\right), k_{1}, p_{2}, q_{2}\right) .\end{cases}
$$

Concerning the reaction function given by $B R_{1}$, the private firm maximizes its profit in the first period by selling its entire $k_{2}$ capacity at the highest $p_{2}$ price, at which it is still not worth for the public firm to sell its entire $k_{1}$ capacity.

\section{Endogenous order of moves}

Assume that there are two periods available to make price-quantity announcements and that both firms are free to choose between the two periods. In stage 1 of the timing game the two firms decide in which time period they will make their decisions. After observing each other's stage 1 choice, they will play in stage 2 , as a function of their stage 1 decisions, a public leadership game, a private leadership game, a simultaneous-move game in period 1 or or simultaneous-move game in period 2.

At first sight the continuum of pure-strategy equilibria makes the solution of the timing game difficult without additional assumptions. However, comparing the solution of the public leadership game with the solutions of the simultaneous-move game, we can see that for the public firm only the best pure-strategy equilibria of the simultaneous-move game is as good as any of the public leadership equilibira (all public leadership SPNE solutions are social welfare equivalent). Hence, it makes no sense for the public firm to delay its price-quantity decision. In an analogous way we can see that private leadership is better for the private firm than the simultaneous-move game. Hence, we obtain the following proposition.

Proposition 4. The equilibrium of the timing game lies at simultaneous moves for both the strong and the weak private firm case. 


\section{Conclusion}

Our main results are collected in the following corollaries. We focus on the differences between the PTO case and the PIA case from the point of view of equilibrium strategies, social welfare effects and equilibrium analysis of the timing game.

Corollary 1. We have at least one pure-strategy equilibrium in both cases for all three orderings of moves.

Corollary 2. In the PTO case the timing of price decisions does not matter, all arising equilibria are payoff-equivalent. In the PIA case both firms want to become the first mover, therefore the equilibrium of the timing game lies at simultaneous moves.

Corollary 3. Comparing the social welfare of the mixed PTO game with the mixed PIA game, we can observe that for any of the three exogenously given ordering of moves the PTO case results in higher social welfare than the PIA case. The same holds for the solutions of the timing games.

\section{References}

Balogh, T., And A. TASnádi (2012): "Price Leadership in a Duopoly with Capacity Constraints and Product Differentiation," Journal of Economics (Zeitschrift für Nationalökonomie), 106, 233-249.

BÁrcena-Ruiz, J. C. (2007): "Endogenous Timing in a Mixed Duopoly: Price Competition," Journal of Economics (Zeitschrift für Nationalökonomie), 91, 263-272.

Boyer, M., And M. Moreaux (1987): "Being a Leader or a Follower: Reflections on the Distribution of Roles in Duopoly," International Journal of Industrial Organization, 5, 175-192.

Cracau, D., And B. Franz (2012): "An experimental study of mixed strategy equilibria in simultaneous price-quantity games," University of Magdeburg, Faculty of Economics and management, Working Paper 17/2012.

Davis, D. (2013): "Advance Production, Inventories and Market Power: An Experimental Investigation," Economic Inquiry, 51, 941-958.

Deneckere, R., And D. Kovenock (1992): "Price Leadership," Review of Economic Studies, 59, 143-162.

Gertner, R. H. (1986): Essays in theoretical industrial organization. Massachusetts Institute of Technology, Ph.D. thesis.

Levitan, R., And M. Shubik (1978): "Duopoly with Price and Quantity as Strategic Variables," International Journal of Game Theory, 7, 1-11.

Matsumura, T. (2003): "Endogenous role in mixed markets: a two production period model," Southern Economic Journal, 70, 403-413.

Mestelman, S., D. Welland, and D. Welland (1987): "Advance Production in Posted Offer Markets," Journal of Economic Behavior and Organization, 8, 249-264. 
PAL, D. (1998): "Endogenous timing in a mixed oligopoly," Economics Letters, 61, 181185.

Phillips, O., D. Menkhaus, and J. Krogmeier (2001): "Production-to-order or production-to-stock: the Endogenous Choice of Institution in Experimental Auction Markets," Journal of Economic Behavior and Organization, 44, 333-345.

Shubik, M. (1955): "A Comparison of Treatments of a Duopoly Problem, Part II," Econometrica, 23, 417-431.

TAsnÁDI, A. (2003): "Endogenous Timing of Moves in an Asymmetric Price-setting Duopoly," Portuguese Economic Journal, 2, 23-35.

(2004): "Production in Advance versus Production to Order," Journal of Economic Behavior and Organization, 54, 191-204.

Tomaru, Y., And K. Kiyono (2010): "Endogenous Timing in Mixed Duopoly with Increasing Marginal Costs," Journal of Institutional and Theoretical Economics, 166, $591-613$.

van Den Berg, A., And I. Bos (2011): "Collusion in a Price-Quantity Oligopoly," Maastricht University, METEOR Working Paper RM/11/039.

Zhu, Q.-T., X.-W. Wu, And L. Sun (2013): "A generalized framework for endogenous timing in duopoly games and an application to price-quantity competition," Journal of Economics (Zeitschrift für Nationalökonomie), pp. forthcoming (http://dx.doi.org/10.1007/s00712-013-0347-3). 